\title{
FERRAMENTA PARA AVALIAÇÃO EMOCIONAL: CONTRIBUIÇÕES PARA O DESIGN DE PRODUTO
}

\author{
TOOL FOR EMOTIONAL EVALUATION: CONTRIBUTIONS TO PRODUCT DESIGN
}

\begin{abstract}
PORSANI, Rodolfo Nucci; Mestrando;Universidade Estadual Júlio de Mesquita Filho -UNESP
rodolfonporsani@gmail.com

LANUTTI, Jamille N. Lima; Doutoranda; Universidade Estadual Júlio de Mesquita Filho -UNESP

jlanutti@gmail.com

MEDOLA,Fausto Orsi; Professor Assistente;Universidade Estadual Júlio de Mesquita Filho -UNESP

faustomedola@faac.unesp.br

PASCHOARELLI,Luis Carlos; Professor Titular;Universidade Estadual Júlio de Mesquita Filho -UNESP paschoarelli@faac.unesp.br
\end{abstract}

\section{Resumo}

Design e Ergonomia são áreas que se complementam em questões relacionadas ao homem e a maneira como ele interage com os objetos em suas atividades da vida cotidiana. Entre os inúmeros elementos envolvidos nessa relação destacam-se os fatores subjetivos, a semântica e a emoção, que tem sido foco de estudos mais recentes. O objetivo deste estudo foi avaliar, por meio de escalas e ferramentas do Design Ergonômico e do Design Emocional, as reações emocionais de usuários identificando quais fatores envolvidos no projeto podem influenciar positivamente ou negativamente na escolha de determinado objeto. Os resultados apontam a necessidade para uma reflexão acerca da importância do Design Ergonômico e Emocional para com a geração de produtos que proporcionem satisfação, conforto e segurança aos mais diferentes usuários.

Palavras-chave: design, ergonomia, design ergonômico, emoção, design emocional.

\section{Abstract}

Design and Ergonomics are areas that complement each other in issues related to man and the way he interacts with objects in his daily life activities. Among the many elements involved in this relationship are subjective factors, semantics and emotion, which have been the focus of more recent studies. The objective of this study was to evaluate, through scales and tools of the Ergonomic Design and Emotional Design, the emotional reactions of users identifying which factors involved in the project can positively or negatively influence the choice of a particular object. The results point to the need for a reflection about the importance of Ergonomic and Emotional Design to the generation of products that provide satisfaction, comfort and safety to the most different users.

Keywords: design, ergonomics, ergonomic design, emotion, emotional design 


\section{INTRODUÇÃO}

A interação entre os seres humanos e os artefatos envolve, preponderantemente, tanto os fatores físicos quanto os subjetivos. E isto ocorre, pois os usuários tendem a associar os objetos do dia a dia a uma semântica pessoal, podendo percebê-los como parte da sua própria identidade, relacionando características pessoais com os produtos que as outras pessoas utilizam e as formas como tais objetos pessoais se apresentam.

Este vínculo entre objeto e produto está relacionado à percepção e emoção de quem faz uso de quaisquer de suas principais funções (práticas, estéticas e simbólicas), e que muitas vezes assume o valor social do artefato, o qual pode ser positivo (status) ou negativo (estigma).

O presente estudo preocupa-se com as questões relacionadas ao homem e a maneira como ele interage com os artefatos em suas atividades da vida diária, e a maneira como o Design e a Ergonomia interpretam esta relação usuário/artefato e estabelecem parâmetros para aprimoramento destas interfaces. Dentre os inúmeros fatores que compõem essa relação destacam-se os elementos subjetivos de percepção e da emoção.

Nesse sentido, verifica-se uma carência de estudos que avaliem aspectos do Design Ergonômico e do Design Emocional, os quais possam dar respostas emocionais dos sujeitos, identificando quais fatores podem influenciar positivamente ou negativamente a percepção acerca do uso de um artefato. Os resultados possibilitaram a análise e reflexão sobre a importância dessas ferramentas, podendo gerar parâmetros para o desenvolvimento de produtos ergonomicamente e emocionalmente satisfatórios e que atendam os anseios dos usuários.

\section{OBJETIVOS}

O objetivo do presente estudo foi avaliar a eficácia de um sistema que trata a emoção por meio das relações semânticas de imagens e de escala de valoração, denominado "EMOG", aplicando esta ferramenta em diferentes produtos, a fim de compreender sua sensibilidade na investigação da emoção gerada pelos mesmos. Para além deste objetivo específico, o propósito final está vinculado às iniciativas de pesquisa e desenvolvimento em Design Emocional e Design Centrado no Usuário.

\section{REFERENCIAL TEÓRICO}

\subsection{Design}

De acordo com o Dicionário Oxford (2012), define-se Design como a planificação ou desenho que demonstra a aparência e/ou função de um objeto. Ação de conceber o planejamento. Arranjo de linhas ou formas para formalizar um padrão ou decoração. Decisão sobre a aparência e funcionalidade de algo. Fazer ou planejar com objetivo prévio.

O design é centro de diversas discussões acerca da atuação, suas condutas, processos, de modo que sua indefinição conceitual provoca em toda discussão que trata sobre o tema, a necessidade de uma explanação sobre o que o autor entende por design (NIEMEYER, 2007).

Para Mizanzuk (2009) dada indefinição conceitual torna o design um meta conceito onde a definição só é possível através de uma contextualização temporal cultural; ou seja, o conceito central sempre é relativo, conforme o contexto da sociedade que se estuda. Contrariando a ideia do Design como mero produtor da beleza, Pereira (2015) apresenta uma definição que coloca esta 
atividade como geradora de tecnologias que auxiliam o homem, e portanto, está centrada em suas capacidades e afazeres, sendo"... uma atividade muito ampla, que consiste em criar produtos, objetos ou sistemas que serão em seguida fabricados e comercializados. Esses objetos vão interagir com o homem ao longo da sua vida facilitando suas atividades diárias e a sua sobrevivência, podendo estar relacionados às atividades profissionais ou cotidianas" (PEREIRA, 2015, p29.).

Para Magalhães (1997), entende-se design tanto como processo (planejamento, desenvolvimento e projeto), como o resultado deste processo (instruções e desenhos técnicos, modelos físicos e digitais e protótipos, e como solução (quanto trata de serviço, artefato ou benefícios gerados por estes meios para a população). Ainda de acordo com Magalhães, comumente relaciona-se design com o aspecto de solução ao ponto que os processos e resultados são correlacionados à atuação do profissional designer.

Por sua vez, Mozota (2011) apresenta uma dupla definição do que é o Design, a primeira linha de pensamento concorda com os autores acima descritos, onde o design apresenta-se como pontual e sob demanda, principalmente voltado ao projeto e produção de artefatos e produtos. A segunda linha de pensamento possui um aspecto de caráter mais estratégico, onde o design é incorporado como uma engrenagem no modelo de negócios. O design, neste contexto, atua de forma ativa dentro das empresas, principalmente nos setores de estratégias mercadológicas, criando demandas para si mesmo e visando alavancar a empresa. Ainda segundo a mesma autora, além do aspecto pontual sob demanda e estratégico o design possui também uma função mediadora entre a indústria e tecnologia e o usuário/consumidor.

De acordo com Cox (2005), em uma definição adotada pelo Design Council - Conselho de Design do Reino Unido ${ }^{1}$, o design interliga a criatividade e a inovação, de maneira a moldar ideias em proposições práticas e atrativas aos usuários ou clientes. A associação de Profissionais de Design APDesign ${ }^{2}$ qualifica o design como uma forma autêntica de expressão social, econômica, cultural e ética, que está comprometida com a evolução e desenvolvimento da qualidade de vida da sociedade como um todo. Já o International Council of Industrial Design - ICSID ${ }^{3}$ (2009) traz como definição que o design é uma atividade criativa que visa determinar qualidades multifacetadas de artefatos, processos, serviços e seus sistemas em ciclos de vida.

\subsection{Design Emocional}

O design de um produto tem em sua essência, a função de satisfazer as necessidades físicas e psíquicas dos usuários e, através das relações estabelecidas durante o processo de uso, desempenha funções práticas, estéticas e simbólicas (LÖBACH, 2001). Conhecer tais funções, bem como a relação entre elas, é algo que pode ser de grande importância para o profissional de design e para o presente estudo.

No entanto, o design orientado para aspectos cognitivos são um grande desafio para a prática projetual, principalmente no que diz respeito ao design orientado para os aspectos emocionais. Afinal, é difícil manipular ou mesmo prever o impacto emocional de um projeto. Isso devido ao fato das emoções serem pessoais, ou seja, diferentes pessoas dão diferentes respostas emocionais para os mesmos produtos (DESMET, 2003).

É difícil encontrar relações entre o design, suas características e as respostas emocionais por

\footnotetext{
1 Conselho de Design do Reino Unido, disponível em: http://WwW.designcouncil.org.uk/

2 Associação de Profissionais de Design, disponível em htTp://www.apdesign.com.br/?Q=apresentacao

3 International Council of Industrial Design, disponível em: wWW.ICSID.org/ABout/about/articles31.htm
} 
elas geradas. Entretanto, recentemente pesquisas vem gerando ferramentas que podem ser utilizadas na compreensão da inter-relação do Design com a Emoção. Trabalhos de três autores são fortemente reconhecidos para a área sendo eles Jordan (1999), Desmet (2002) e Norman (2008).

Jordan (1999) investigou diferentes fontes de prazer relacionadas aos objetos. Propôs que elas podem ser fisiológicas (sensações corporais), psicológicas (ganhos relacionados ao 'eu"), sociológicas (interação social) e ideológicas (estimulação sensorial).

Desmet (2002), em adição, estudou a forma como a aparência de um produto pode evocar emoções, e propôs que as emoções são respostas automáticas do usuário em relação ao efeito de um produto sob seu bem-estar.

Norman (2008) também focou seus trabalhos na forma como as pessoas lidam e utilizam as informações e a influência desse processo nas emoções, identificando três níveis de processamento, sendo o primeiro o nível visceral (relacionado à percepção direta), o segundo o comportamental (envolvendo respostas aprendidas, mas automáticas, emitidas pelo usuário) e o terceiro o reflexivo (partindo de pensamento consciente). Propôs, a partir de seus estudos, que o Design poderia seguir três diferentes estratégias: design para aparência (ou design visceral), design para conforto/facilidade de uso (design comportamental) ou design para significado reflexivo (design reflexivo), demonstrando grande preocupação em compreender a relação da emoção com relação ao uso dos produtos.

Para Cantelli (2009, p.2), todo fato que promova uma emoção é registrado na memória afetiva do ser humano, e isso gera uma relação significativa entre situações do cotidiano e as experiências passadas (sejam elas positivas ou negativas). Esse ativamento sensorial provocado pelas emoções causa no sujeito determinadas ações, em razão de que o cérebro cria um sentimento de acordo com a percepção do usuário, esta percepção está relacionada intrinsecamente às emoções lembradas e sentidas tanto em forma de retroprojeção como em forma de projeção (passado e presente), respectivamente.

Design emocional, é considerada uma área integrante as demais áreas do design de maior cunho científico. Trabalha com pesquisa, teoria, métodos e resultados, que abordam diversas áreas de conhecimento, que possibilitam prever resultados desejados a fim de atender às necessidades e os desejos dos usuários, pensando de forma estratégica com foco no usuário (SILVA 2013).

Ainda segundo a mesma autora, o Design Emocional não objetiva a manipulação ou controle das emoções do usuário, mas interpreta os desejos e anseios que levam uma pessoa a consumir determinado produto, por meio da emoção. Para isso o Design Emocional se desenvolve, através de estudos e pesquisas, no sentido criar artefatos que correspondam às necessidades emocionais dos indivíduos .

\subsection{UCD - Design Centrado no Usuário}

O Design Centrado no Usuário (UCD), vem como uma ferramenta metodológica para auxiliar a avaliação da inovação e da eficiência de produtos destinados a suprir as necessidades dos usuários. Tal ferramenta aplicada ao processo de concepção do produto favorece o surgimento de respostas, experiências e sugestões relevantes ao processo de projeto de produto, antes da finalização e comercialização do mesmo.

Dentro do processo UCD recomenda-se que aqueles que usufruirão do produto final participem do processo de projeto, dando retorno crítico e auxiliando na elaboração do produto 
final, ao invés de serem consultados somente quando o produto estiver finalizado.

A experimentação do usuário dentro do UCD é para Royo (2008) um "grupo de sensações, valores e conclusões, que são obtidos pelo usuário a partir do uso de um equipamento, incluindo reações físicas e emocionais" e para Mallin (2015), " para alcançar o sucesso com o projeto centrado no usuário, é fundamental considerar o contexto do uso, a tarefa a ser cumprida e o universo cultural envolvido, ampliando assim a compreensão das necessidades do usuário."

Ainda segundo Mallin, em estudo que trata sobre Tecnologia Assistiva, "precisamos estabelecer dois novos elos na cadeia do processo de inovação: colocar o usuário no centro da atenção e outro foco na emoção para evitar assumir o risco de fazer ajustes ao invés de trazer inovação para projetos".

\subsection{Design Ergonômico}

Design Ergonômico (DE), surgiu com Paschoarelli (2003), e tem como definição “... aplicação do conhecimento ergonômico no projeto de dispositivos tecnológicos, com o objetivo de alcançar produtos e sistemas seguros, confortáveis, eficientes, efetivos e aceitáveis". E segundo o mesmo autor, visa proporcionar condições de uso em que o artefato esteja adequada aos anseios e capacidades dos usuários.

A Ergonomia, "disciplina científica que estuda as interações entre os seres humanos e outros elementos do sistema" (IIDA e GUIMARÃES, 2016, p.4), também tem realizado estudos relacionados às questões cognitivas da interação do homem com o mundo a sua volta, mais especificamente relacionadas ao local e aos seus instrumentos de trabalho. Assim, a integração entre Inteligência Emocional e Ergonomia busca capacitar a dinâmica de trabalho, garantindo bem estar que vai além do que é fisiológico, e que Siddique (2004) chamou de Ergonomia Emocional.

No entanto, para o Design Ergonômico o conceito de trabalho ultrapassa o espaço físico de uma empresa ou instituição onde se realiza atividade remunerada, ou seja, diz respeito a toda interação do homem com a tecnologia que o auxilia nas atividades da vida diária.

Muitos são os produtos para as quais a Ergonomia, relacionada a critérios emocionais, poderia dar grande contribuição, preocupando-se, por exemplo, em tornar produtos com estigmas sociais ruins mais amigáveis, sem, no entanto desfavorecer seus aspectos técnicos e de uso.

\section{MATERIAIS E MÉTODOS}

O presente estudo caracterizou-se como exploratório e transversal. Por envolver a participação de seres humanos, foi aplicado um TCLE (Termo de Consentimento Livre e Esclarecido), atendendo à Resolução 196/96-CNS-MS e à Norma ERG BR 1002, do Código de Deontologia do Ergonomista Certificado (ABERGO, 2003). Tendo sido submetido ao Comitê de Ética da Unesp - Bauru e aprovado (processo CAAE 59717916.5.0000.5663), o preenchimento do participante no TCLE representava que o mesmo estava apto e aceitou sua participação.

Assim, os participantes voluntários preencheram um TCLE, onde eram esclarecidos quanto aos objetivos do projeto, a forma como a coleta de dados seria realizada - meio digital - e sobre o fato de que nenhum procedimento seria invasivo ou causaria desconforto, constrangimento ou risco à saúde e caso apresentassem dúvidas, poderiam entrar em contato com os pesquisadores para esclarecimentos. 


\subsection{Participantes}

O estudo contou com a participação de 10 indivíduos de diferentes faixas etárias, divididas em dois grupos: 4 participantes do gênero masculino, com idade média de 40,00 anos e desvio padrão de 18,80; e 6 participantes do gênero feminino, com idade média de 41,50 anos e desvio padrão de 14,92.

\subsection{Ferramenta}

Baseado na compreensão de que semântica, emoção e usabilidade atuam em sintonia para construção de uma interação homem-tecnologia (OVERBEEK, 2002), desenvolveu-se uma ferramenta denominada EMOG, a qual trata da análise da emoção por meio das relações semânticas de imagens e de escala de valoração, podendo ser aplicado em diferentes interações entre usuários e artefatos.

O EMOG foi desenvolvido no formato de um protocolo eletrônico digital, especificamente elaborado para aplicação na Internet, no qual solicitou-se aos sujeitos que selecionassem uma imagem que melhor representa-se determinada emoção de acordo com sua percepção (figura 1a), e posteriormente selecionar a emoção baseada na imagem anteriormente selecionada e uma escala de valoração de intensidade, diante das imagens de objetos a serem avaliados (figura $1 b$ ).

Figura 1: Layout da Ferramenta EMOG. Relação Emoção X Imagem (à esquerda) Relação Emoção/Imagem X Objeto a ser avaliado (à direita).
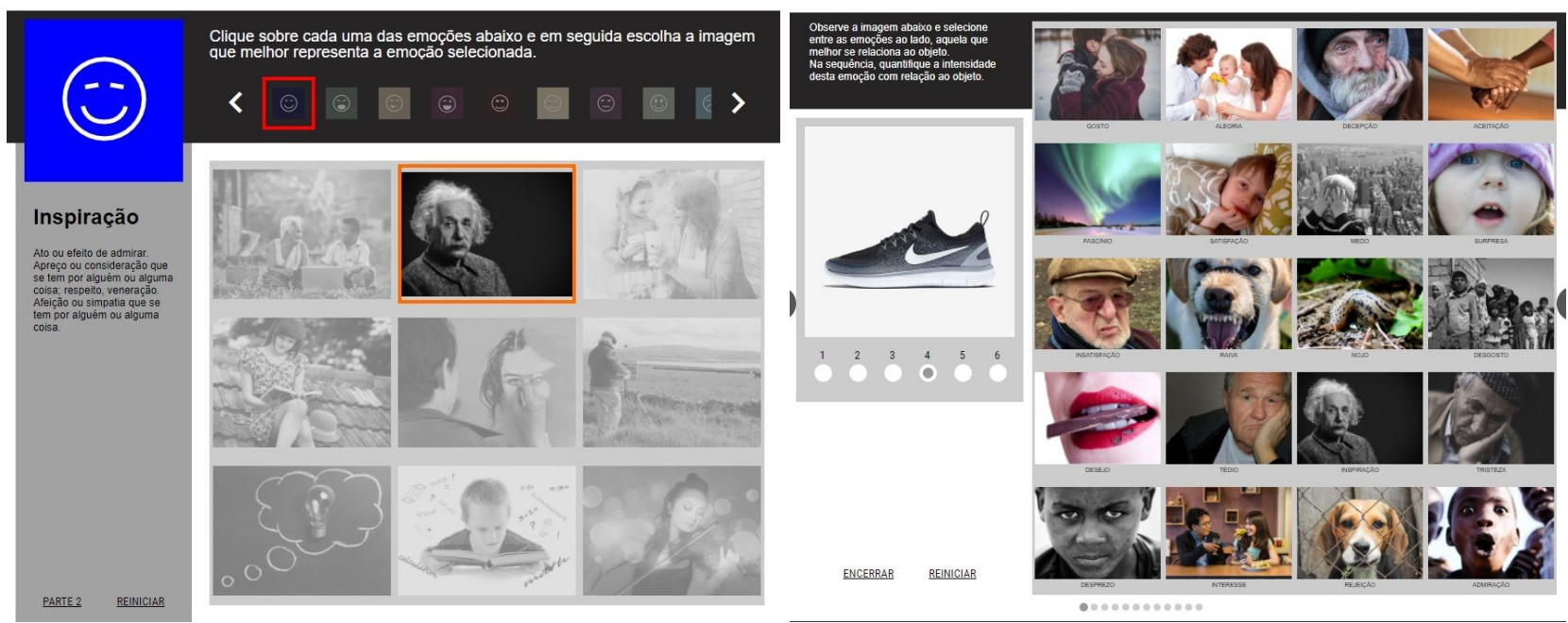

Fonte: Os Autores

Na plataforma EMOG foram disponibilizadas vinte emoções (tabela 1), sendo 10 positivas e 10 negativas. Para cada emoção foram disponibilizadas 9 imagens pré-selecionadas e um pequeno texto descritivo a fim de que o voluntário escolhesse a figura que segundo ele, melhor representaria a emoção em destaque. 
Tabela 1: Lista de Emoções positivas e negativas medidas pelo EMOG

\begin{tabular}{|c|c|}
\hline EMOÇõES POSITIVAS & EMOçÕES NEGATIVAS \\
\hline Alegria & Nojo \\
Desejo & Desapontamento \\
Inspiração & Desprezo \\
Admiração & Insatisfação \\
Satisfação & Rejeição \\
Aceitação & Tédio \\
Interesse & Desgosto \\
Gosto & Raiva \\
Fascínio & Medo \\
Surpresa & Fonte: Os Autores
\end{tabular}

Fonte: Os Autores

Posteriormente a essa etapa, foram apresentadas 4 figuras de óculos graduados distintos e 4 figuras de calçados (tenis) distintos, junto às vinte emoções correlacionadas com as respectivas figuras selecionadas na primeira etapa da pesquisa e uma barra de intensidade para a valoração da emoção mais pertinente que o usuário sentiu ao observar a imagem do produto.

Foram utilizados servidor web HTTP Apache, sistema de gestão de base de dados relacional MYSQL e a linguagem de programação PHP utilizado para o desenvolvimento de conteúdo dinâmico e para facilitar a análise de dados, o sistema exporta os resultados em tabelas no formato excel. Além disso, foram coletados dados para caracterização da amostra - Data de nascimento, Profissão, Gênero, entre outros (figura 2).

Figura 2: tela de cadastro do EMOG.

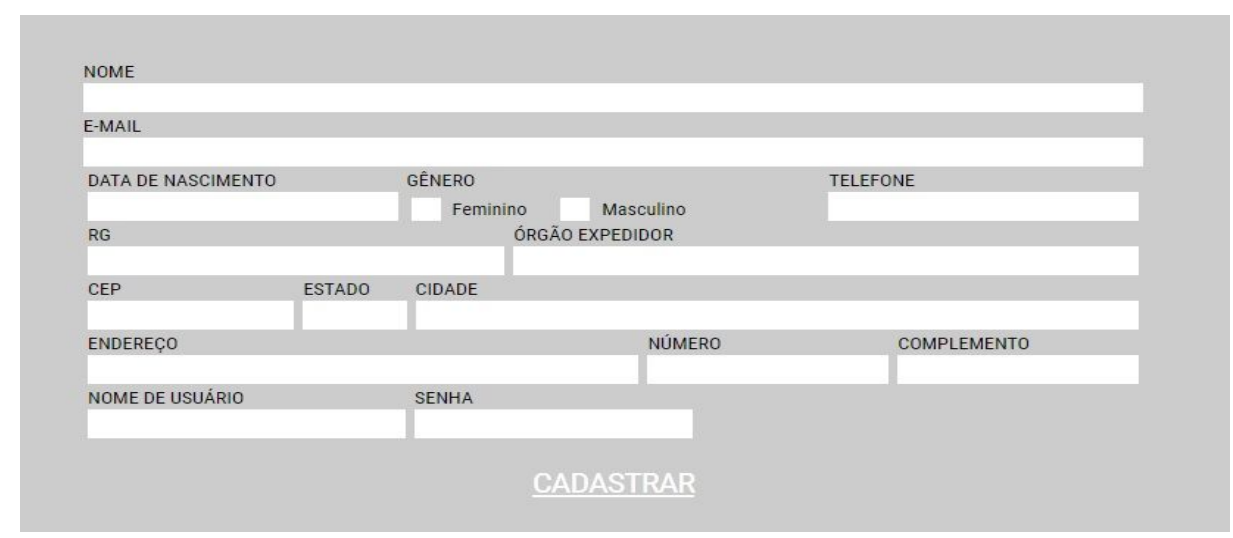

Fonte: Os Autores 


\subsection{Procedimentos}

Tratando-se de um protocolo digital, os dados foram coletados com o envio de um link, por meio do qual as pessoas respondiam o TCLE, preenchendo o cadastro e respondendo ao protocolo. O envio deste link ocorreu na segunda quinzena de julho de 2017 e a plataforma ficou aberta para pré-testes por 30 dias. Os dados obtidos foram organizados em planilhas no Microsoft Excel, onde foi possível reconhecer as emoções mais assinaladas e suas intensidades. Todo estudo foi desenvolvimento no Laboratório de Ergonomia e Interfaces - LEI- da UNESP (Campus Bauru - SP - Brasil). Os dados foram analisados por meio de estatística descritiva, sendo analisadas as frequências com que as imagens que caracterizam as emoções semanticamente apareciam.

\subsection{Objetos de Estudo}

Para realização do estudo foram selecionados dois grupos de objetos para análise, sendo 4 Óculos graduados, com modelos, marcas, cores e materiais diferentes; e 4 calçados que embora tenham valores de compra bastante diferentes, são todos da mesma marca e possuem cores e formas semelhantes (figura 3). No entanto para análise não foram divulgados os valores comerciais, pois acredita-se que poderia influenciar no desejo de consumo e consequentemente nas emoções.

Figura 3 - Categoria Óculos Graduado

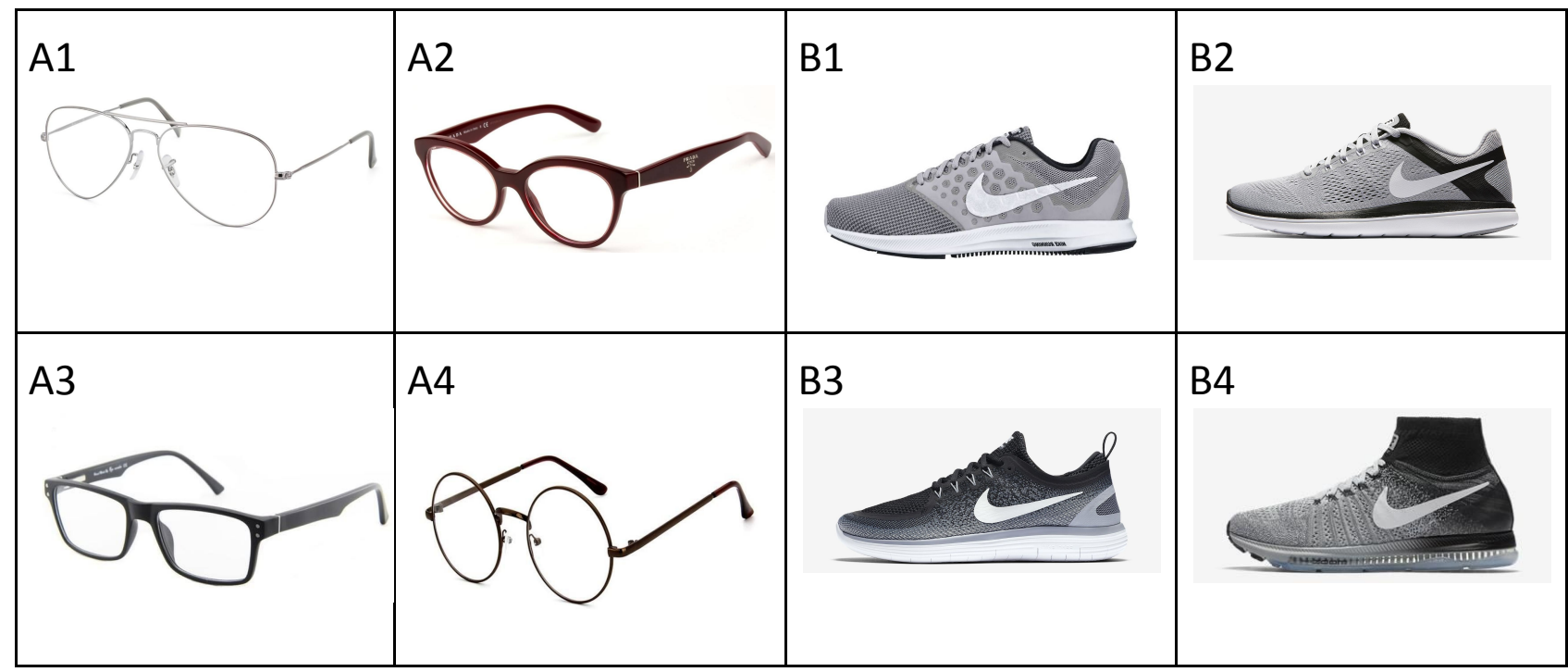

Fonte:pixabay.com/pt

\section{Resultados}

Os resultados descritivos são apresentados na figura 4. Também foram organizados modelos nos quais é permitido analisar tanto a frequência (Figura 5), quanto às médias e desvio padrão para cada emoção (Figura 6).

Nota-se que que tanto em relação aos calçados (B1, B2, B3 e B4), como em relação a maioria dos óculos ( $A 2, A 3$ e $A 4)$ ocorreu maior frequência de emoções positivas do que negativas. Com exceção para o óculos $A 1$, no qual ocorreu empate. 
Figura 4 - Imagens que foram selecionadas com maior frequência.

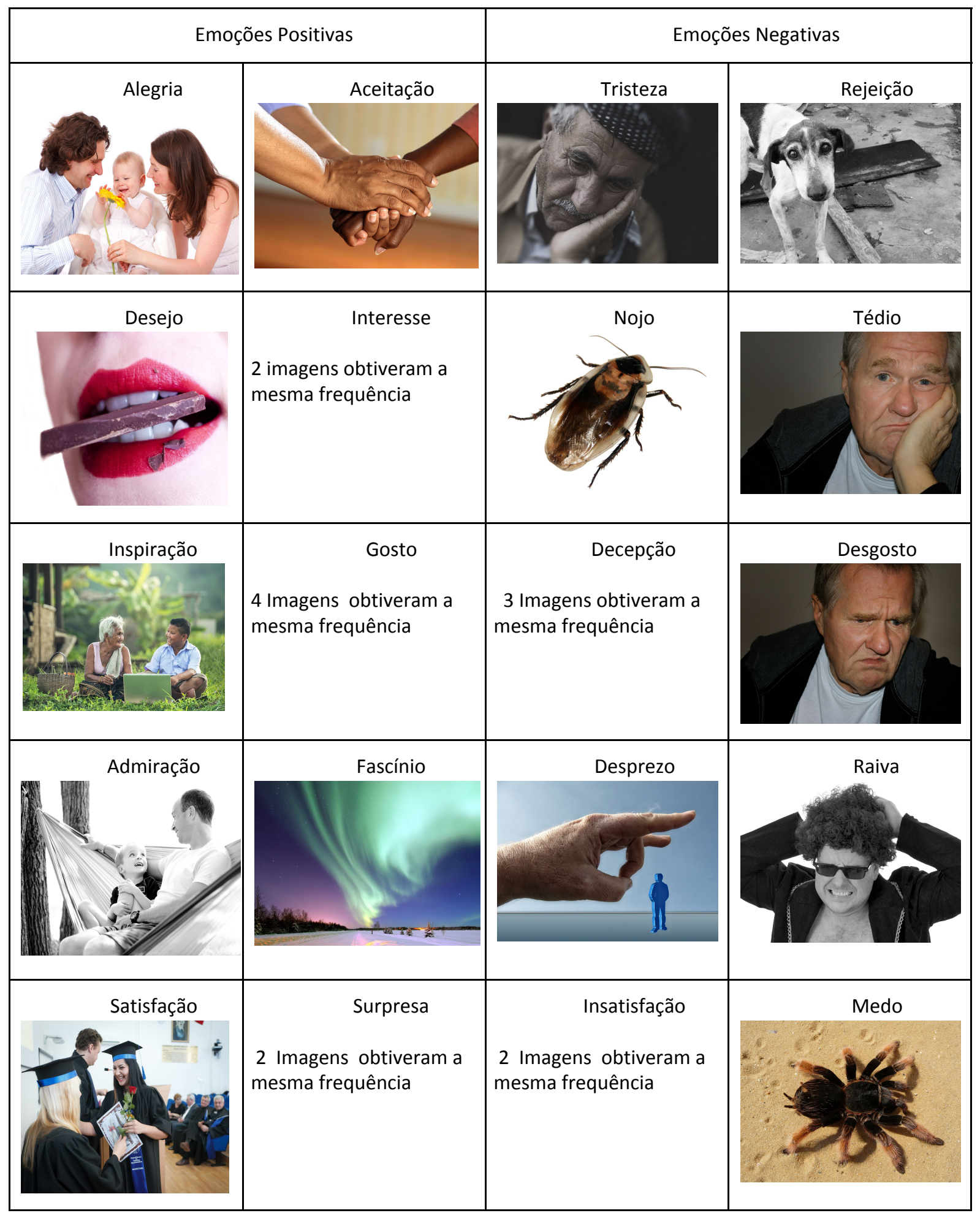

Fonte: Os Autores

Na Figura 5, percebe-se a expressiva superioridade de frequências emocionais positivas tanto para os calçados quanto para a maioria dos óculos graduados, destacando-se o item A1, onde ocorreu um equilíbrio de emoções. 
Figura 5 - frequências emocionais positivas e negativas

10

8

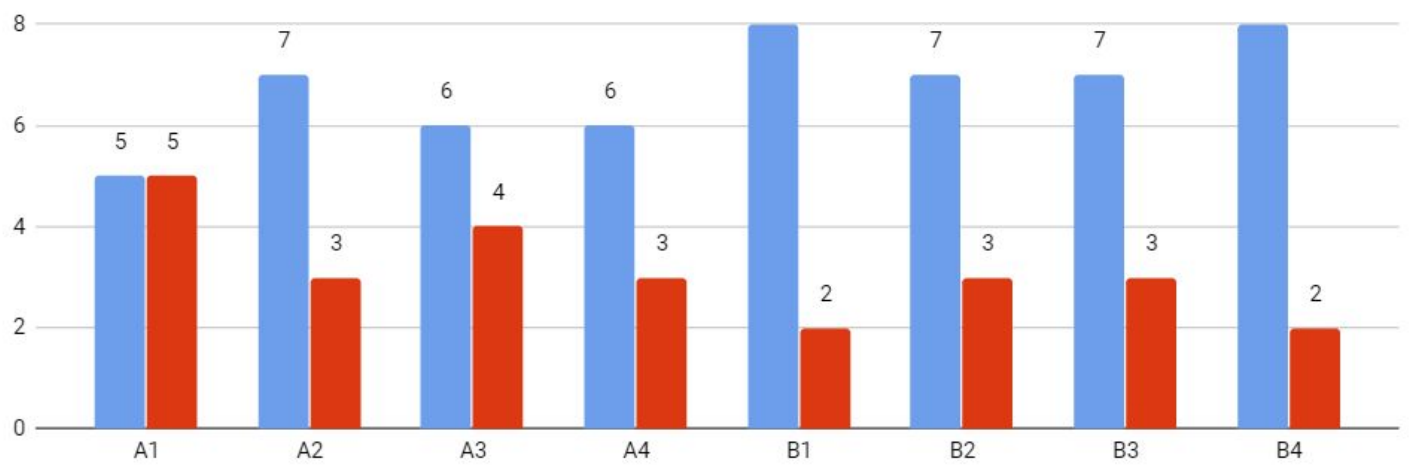

PONTOS POSITIVOS P PONTOS NEGATIVOS

Fonte: Os Autores

Já na Figura 6, nota-se também a maior intensidade de emoções positivas, tanto para os óculos graduados quanto para a maioria dos calçados, destacando-se o item B3, onde ocorreu uma inversão de valores e a intensidade de emoções negativas apresentaram-se superiores.

Figura 6 - Médias de intensidades emocionais positivas e negativas

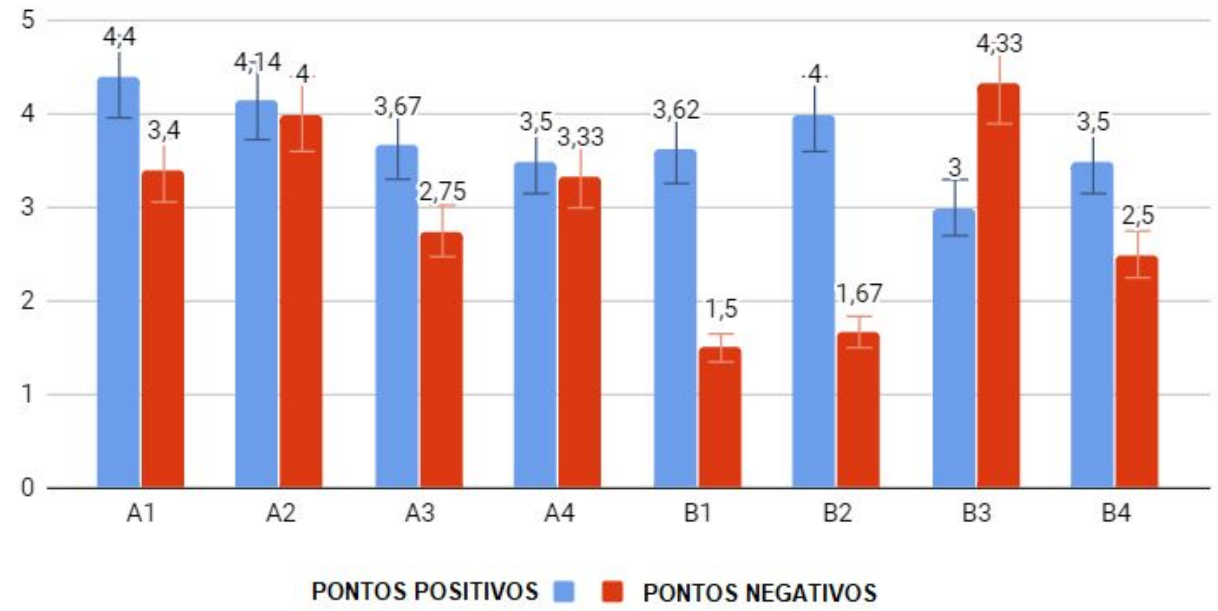

Fonte: Os Autores

Observou-se que os resultados apresentaram diferenças expressivas entre os objetos estudados. Os artefatos Tênis fomentaram mais emoções positivas que os óculos graduados, contudo a média positiva de intensidade emocional dos óculos graduados foi maior (soma total óculos graduado: 29,19 / soma total calçados: 24,12 ).

Outro fator interessante foram os resultados obtidos acerca dos modelos de calçados, os quais foram padronizados os fatores de cor e a marca, porém (como mencionado anteriormente) foi omitido dos participantes o valor monetário dos produtos. O modelo B1 custando em média $\mathrm{R} \$ 199$, o modelo $B 2$ custando em média $\mathrm{R} \$ 299$, o modelo $B 3$ custando em média $\mathrm{R} \$ 499$ e por fim o modelo B4 com valor de $\mathrm{R} \$ 899$. 
Notou-se dentro do segmento de calçados que os modelos B1 e B2 (mais econômicos) apresentaram médias de intensidade de sentimentos positivos maiores que os modelos B3 e B4 (mais caros), e que especificamente o modelo B3 apresentou a maior média de intensidade de sentimento negativo e o maior desvio padrão negativo, superando todos os outros objetos nesses fatores.

\section{CONSIDERAÇÕES FINAIS}

A revisão bibliográfica mostrou-se importante para o embasamento teórico, preparando o campo para o estudo das áreas correlatas aos estudos das emoções aplicadas à artefatos. A ferramenta desenvolvida, EMOG, provou-se eficiente na coleta de dados relativos às emoções captadas pelos sujeitos ao analisarem o banco de imagens pré-selecionadas.

O presente artigo é importante por discutir alternativas de ferramentas de avaliação das áreas que circundam o Design e Ergonomia, bem como por ajudar a esclarecer os conceitos de Design Centrado no Usuário, Design Ergonômico e Design Emocional, bem como da importância das emoções na relação Usuário e Artefato.

O EMOG apresentou-se como uma ferramenta sensível aos aspectos emocionais da interação usuário/produto, visto que permitiu a avaliação de critérios de percepção visual, de interesse do Design. Constatou-se que os 4 óculos graduados apresentados em modelos, cores, formas e texturas diferentes representaram um estímulo maior, o que provavelmente facilitou com que os sujeitos diferenciassem as emoções entre positivas e negativas e as percebessem com maiores intensidade.

Os 4 modelos de tênis padronizados em marca e cor, com valores monetários omitidos, representando um estímulo visual menor, apresentaram maiores pontuações positivas, contudo com médias de intensidades menores se comparadas com os óculos, o que pode ser explicado pela dificuldade de diferenciação emocional entre positiva e negativa, devido ao uso de uma cor padronizada (cinza), resultando em uma menor intensidade emocional.

De maneira geral, pode-se afirmar que o EMOG foi uma ferramenta sensível às emoções envolvidas nas relações semânticas de imagens e de escala de valoração, no presente estudo. Apesar disto, novos estudos devem contribuir expressivamente para as futuras investigações sobre a emoção na interação entre usuários e artefatos.

\section{AGRADECIMENTOS}

Agradecimentos especiais ao CNPQ (Proc. PIBITI-39391/2016) e à CAPES (Proc. 88887.095645/2015-0).

\section{REFERÊNCIAS BIBLIOGRÁFICAS}

COX, Sir George. The Cox Review of Creativity in Business: building on the UK's strengths. Londres:National Archives, 2005.

DESMET, P. Designing emotions. Delft, The Netherlands. Tese de Doutorado. Delft University of Technology, 225 p. 2002. 
DESMET, P.; DIJKHUIS, E. A Wheelchair can be Fun: A Case of Emotion-driven Design. In:Proceedings of DPPI03, Pittsburg, USA. In press.2003

IIDA, I.; GUIMARÃES, L.B.M. Ergonomia: Projeto e Produção. São Paulo: Editora Edgard Blücher, 3a ed., 2016.

JORDAN, P. Pleasure with products: Human factors for body, mind and soul. In: W.S. GREEN; P.W. (eds.), Human factors in product design: Current practice and future trends. London, Taylor \& Francis, p. 206-217., 1999.

JORDAN (eds.), Human factors in product design: Current practice and future trends. London, Taylor \& Francis, p. 206-217.1999.

LOBACH, B. Design industrial: bases para a configuração dos produtos industriais. São Paulo: Edgard Blucher, 2001.

MAGALHÃES, Claudio Freitas de. Design Estratégico: Integração e Ação do Design Industrial dentro das Empresas. Rio de Janeiro: SENAI/ DN, SENAI/CETIQ, CNPq, IBICT, PADCT, TIB, 1997.

MALLIN, S. S. V., CARVALHO, H. G., Tecnologia Assistiva e Design Centrado no Usuário: A emoção como elemento para a inovação , 6th International Conference on Applied Human Factors and Ergonomics( AHFE 2015) and the Affiliated Conferences AHFE 2015.

MIZANZUK, Ivan Alexander. O Conceito de Design na época de sua indeterminação epistemológica. In: CIPED, 5.,2009; Bauru. Anais... Bauru:UNESP, 2009.

MOZOTA, Brigitte. Borja de. Gestão de design: usando o design para construir um valor de marca e inovação corporativa. Porto Alegre: Bookman, 2011.

NIEMEYER, Lucy. Design no Brasil: Origens e instalação. Rio de Janeiro: Editora 2AB, 2007.

NORMAN, D. A. Design Emocional: Porque adoramos (ou detestamos) os objetos do dia-a-dia, Rio de Janeiro. Ed.: Rocco, 2008.

OVERBEEK, K.; BLYTHE, M. A.; MONK, A. F.; WHIGHT, P. C. Human-computer interaction series. New York: Kluwer Academic Publishers, 2002.

OXFORD, Dicionário. University Press, 2012. Disponível :https://www.oxforddictionaries.com

PASCHOARELLI, L.C. Usabilidade aplicada ao Design Ergonômico de Transdutores de Ultra-sonografia: Uma Proposta Metodológica para Avaliação e Análise do Produto. Tese de Doutorado pela Universidade Federal de São Carlos, 2003. pg 26

PEREIRA, Douglas Daniel, $\mathbf{O}$ uso da modelagem aplicada à ergonomia no desenvolvimento de produtos, Bauru, 2015. p.29

ROYO,J. Digital Design, Fundamentals of Design Collection. São Paulo Rosari Editions, 2008

SIDDIQUE, Z. Conceptualizing Emotional Ergonomics and Exploring Ways to Empower Workplace Dynamics. In: McCabe, T. P. Contemporary Ergonomics. p. 540-544. 2004.

SILVA, M.F. DESIGN E EMOÇÃO: novos modos de vida, novas reconfigurações de objetos e valores, 20013, pg.9. 